\title{
Experimental pulmonary embolism due to red cell aggregation
}

\author{
ANTONY DE BONO AND NICOS GAZETOPOULOS
}

From the Thoracic Surgery and Cardiology Departments, Guy's Hospital, London, S.E.I

The effect of clumping or aggregation of red blood cells on flow has recently become of increasing interest. Unimpeded flow through the capillaries depends to a great extent upon the red cells remaining separate in the plasma. Clumping causes blockage of the blood vessels, the extent of which is governed by the rate of flow and perfusion pressure, and the relative size of the clumps and lumen of the vessel. This blocking is manifest as an increase in resistance, as in pulmonary hypertension, and can, combined with other factors such as low perfusion pressure, vasoconstriction, and a low oxygen saturation, cause widespread tissue ischaemia, especially in the brain and kidney, which are sensitive to lack of oxygen (Knisely, Eliot, and Bloch, 1945 ; Heimbecker and Bigelow, 1950).

Intravascular aggregation of red cells occurs naturally in many clinical conditions, especially where tissue damage is a feature. These include traumatic shock, burns, cardiac infarcts, and during extra-corporeal circulation (Gelin, 1956). This can be observed in the conjunctival vessels and is reflected by a high sedimentation rate. It can also be caused in vivo and in vitro by the injection of certain substances into the blood. These include high molecular weight dextran, some radio-opaque dyes, and other large molecules such as hexadimethrine bromide ('polybrene', Abbott).

We have chosen the latter to produce experimental red cell aggregation and to study its effects on the circulation for two reasons. It is a powerful and reliable agent for causing aggregation; and it is an efficient neutralizer of heparin (Preston, Hohf, and Trippel, 1956) and as such is used at the end of cardiopulmonary by-pass. We have studied its circulatory effects in detail in order to isolate the effects of red cell aggregation that cause pulmonary hypertension.

There is no general agreement as to the effects of this drug on the circulation if given other than extremely slowly and in small amounts. A prolonged systemic hypotension has been reported (Weiss, Gilman, Catenacci, and Osterberg, 1958 ;
Kimura, Young, Stein, and Richards, 1959 ; Egerton and Robinson, 1961). On the other hand, an early rise in pulmonary artery pressure has been found by others (Rothnie and Kinmonth, 1960 ; Holemans and Adamis, 1962). The latter put forward the suggestion that the changes in pressure could be due to blocking of the pulmonary vessels by red cell aggregates seen in vitro.

Other substances causing pulmonary hypertension on intravenous injection were also studied and their actions compared.

The results show how red cell aggregation can produce pulmonary hypertension due to mechanical blocking of the pulmonary vessels. ${ }^{1}$ The circulatory effects described in this paper may help in the investigation of such clinical conditions as pulmonary embolism and pulmonary hypertension of the obliterative type, as well as in stressing the danger of substances likely to cause aggregation.

\section{METHOD}

IN VIvo Twenty-six mongrel dogs weighing 9 to $14 \mathrm{~kg}$. were anaesthetized with intravenous sodium thiopentone. A mid-sternal thoracotomy was performed. Thin-walled P.V.C. catheters were placed in the femoral vessels, the atria, the ventricles, the main pulmonary artery, and a pulmonary vein.

Pressures were measured with Sanborn electromanometers. Zero pressure was taken as at the level of the right atrium.

Control recordings were made for three minutes before the injections, continuously during the injections, and for 10 minutes after the injections. Simultaneous electrocardiograph leads I and II were recorded during the procedure. Blood samples were collected and measured for oxygen saturation, $p H$, haematocrit, and sedimentation rate as described below. Samples of segments of the lung for histological examination were taken before, during, and after the injections.

1 This method of producing red cell clumps in vivo is also being used to produce chronic pulmonary hypertension, and to studv the effects of red cell aggregation on other organs such as the heart. brain, gut, and kidney. This will be described in subsequen papers. 
A total of 120 injections were made at various sites in the circulation. A number of these were made before the chest was opened. The standard dose of hexadimethrine used, unless otherwise stated, was $5 \mathrm{mg}$. $/ \mathrm{kg}$. injected over a period of five seconds. This dose is not much larger than that frequently used clinically, but the speed of injection is more rapid.

The effects of the first injections in any experiment were compared with subsequent injections after neutralizing doses of heparin in equivalent amounts had been given (1:1 mg.) and all pressures were at control levels and stable.

The effects of larger or more prolonged injections of hexadimethrine were also studied, as were the modifying effects of various substances described below.

Five rabbits were anaesthetized with sodium pentobarbital ('nembutal') and similar procedures carried out.

IN VITRo The action of hexadimethrine on the red blood cells of various species was studied in vitro at different concentrations. These were compared with the effects of dextrans of different molecular weights, hypertonic solutions, heparin, and other substances.

\section{RESULTS}

INTRAVENOUS INJECTIONS The first change after the intravenous injection of hexadimethrine $(5 \mathrm{mg}$. $/ \mathrm{kg}$.) was an acute rise in pulmonary artery pressure (Figs. 1 and 2). In each of eight dogs with open chests the rise in pulmonary artery pressure started 4 seconds after the beginning of the injection into the femoral vein and reached a peak about 5 seconds later (3-8 sec.). The average systolic pulmonary artery pressure increased from a control level of $15 \mathrm{~mm}$. $\mathrm{Hg}(10-$ $22 \mathrm{~mm}$. $\mathrm{Hg}$ ) to $44 \mathrm{~mm}$. $\mathrm{Hg}(32-56 \mathrm{~mm}$. $\mathrm{Hg})$, a mean rise of $300 \%(240-370 \%)$. The right ventricular systolic pressure increased with that of the pulmonary artery, and the mean right atrial pressure was raised a few millimetres at this time. All these pressure changes followed a standard injection and were maintained for about 6 seconds and then fell to a level at, or a

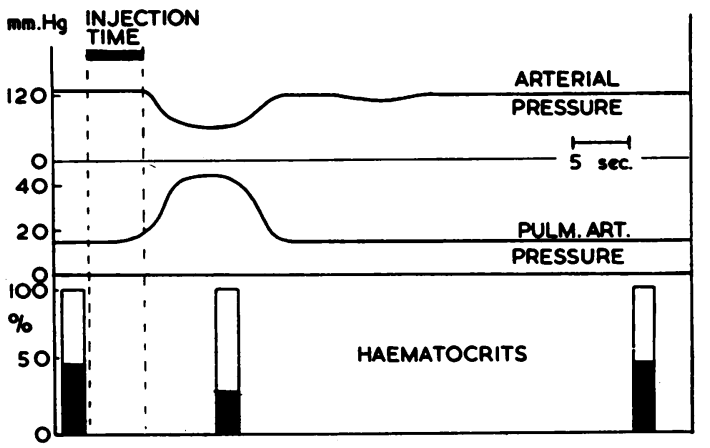

FIG. 2. Diagram of pressure changes in pulmonary artery and systemic arteries after intravenous injection of hexadimethrine, showing drop in arterial haematocrit coinciding with pulmonary hypertension.

few millimetres above, the control level to which they returned after a minute or two.

About one second after the start of the rise in pulmonary artery pressure there was a corresponding steep fall in systemic pressure, which reached its nadir as the pulmonary hypertension reached its peak. From an average systolic pressure of $126 \mathrm{~mm}$. $\mathrm{Hg}(85-168$ $\mathrm{mm} . \mathrm{Hg}$ ) this dropped to $68 \mathrm{~mm} . \mathrm{Hg}(42-100 \mathrm{~mm}$. $\mathrm{Hg})$, which represented a drop of $54 \%(44-68 \%)$. The pulse pressure diminished simultaneously with the fall in left ventricular systolic pressure. The left atrial and pulmonary vein pressures fell consistently. These pressures returned to normal with the recovery of the pulmonary artery pressure. Subsequently there was a small second drop in systemic pressure.

In two of the eight dogs with open chests there was an additional third drop in systemic pressure (Fig. 3). This was more pronounced and prolonged than the first drop, being of the order of 60 to 100 $\mathrm{mm}$. $\mathrm{Hg}$ and lasting from 4 to 6 minutes. It started about 25 seconds after the first effect (pulmonary hypertension, etc.). There was no rise in pulmonary artery pressure at this stage. This prolonged and delayed fall in systemic pressure was found consistently
FIG. 1. Simultaneous recording of systemic and pulmonary artery pressures after intravenous injection of hexadimethrine.

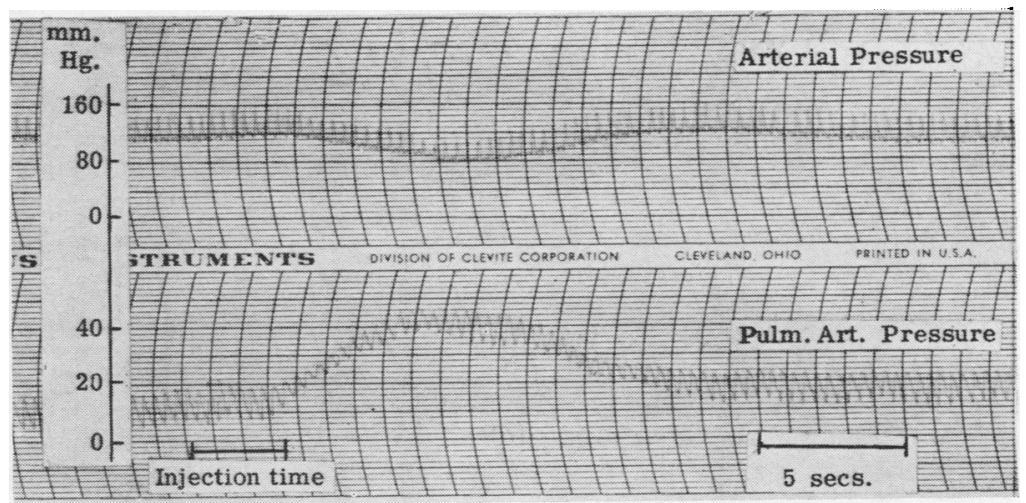




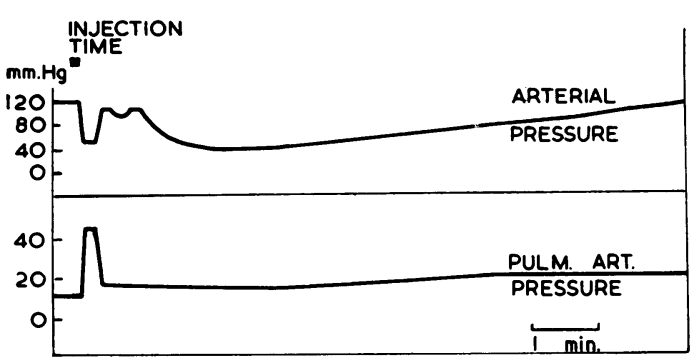

FIG. 3. Diagram of pulmonary artery and systemic pressure changes after intravenous injection of hexadimethrine, showing secondary prolonged fall in systemic pressure.

on first injections into four closed-chest intact dogs and is produced in intact dogs by injections of hexadimethrine too small or too slow to give rise to the effects of pulmonary hypertension. We regard this delayed effect as non-specific. and the rise in pulmonary artery pressure together with a fall in systemic pressure as the main or primary effect.

REPEATED INJECTIONS PROXIMAL AND DISTAL TO THE LUNGS After the first injections pressures were allowed to return to normal, and a neutralizing dose of heparin was given. This routine was repeated for all subsequent injections.

Injections of the standard dose into the circulation proximal to the lungs (veins, right atrium, right ventricle, and pulmonary artery) produced identical pressure changes which differed only in that the time lag between the injection and the onset of the pressure changes varied directly with the distance between the site of injection and the lung.

As no direct method of measuring a rapidly changing flow through the lungs was available, a wide-bore polythene cannula was tied into one of the pulmonary veins, and direct timed measurements were made on the effluent. This was done in four dogs. There was

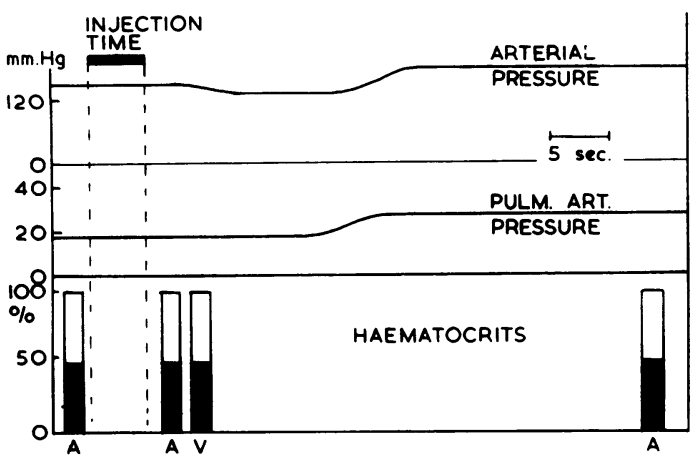

FIG. 4. Diagram of pressure changes after injection of hexadimethrine distal to the lungs. There is no change in arterial and venous haematocrits ( $A$ and $V$ ). a sharp drop in flow corresponding to the period of $\stackrel{\overrightarrow{\bar{S}}}{\overrightarrow{0}}$ pulmonary hypertension.

There were no significant changes in the electrocardiograms apart from an occasional $P$ pulmonale.

The primary effect (pulmonary hypertension, etc.) $\vec{\nabla}$ was always reproducible after standard injections, $\varrho$ whereas the delayed non-specific drop in systemic pressure was only found after the first injection and $\vec{\circ}$ typically in intact dogs.

In six dogs injections were made into the left atrium, left ventricle, and aorta (Fig. 4). There was o no discernible rise in pulmonary artery pressure either directly or on recirculation. The circulatory effects of these injections were confined to a small drop in sys- $\overrightarrow{0}$ temic pressure of about $25 \mathrm{~mm}$. $\mathrm{Hg}$ which started $\omega$ about 8 seconds after the beginning of the injection and remained at this level for about 30 seconds. This was followed by a period of systemic hypertension 윽 before the pressure returned to normal. This overshoot was possibly due to an increase in cardiac out- $₹$ put as the pulmonary artery pressure was also slightly raised at this time.

DRUGS MODIFYING THE CIRCULATORY EFFECTS OF $\$$ HEXADIMETHRINE An intravenous injection of hexadimethrine in a previously heparinized dog induced the usual primary response. However, the injection of a mixture, in the same syringe, of an equivalent amount of heparin and hexadimethrine gave no circulatory response. Synchronous injection of equivalent amounts of heparin and hexadimethrine into the two femoral veins caused no pressure change but if the heparin was injected into the left atrium there was a typical response. It was clear that the local concentration of unneutralized hexadimethrine determined the pulmonary hypertensive response.

This effect was not influenced by atropine or by bilateral vagotomy. It was reproduced in isolated perfused lungs.

Intravenous injection of hexadimethrine during a steady injection of acetylcholine gave a typical primary response. Moreover, during the period of pulmonary hypertension produced by the hexadimethrine, the injection of acetylcholine did not modify the pulmonary artery pressure, as has been described in conditions of pulmonary hypertension due primarily to vasoconstriction (Harris, 1957 ; Rudolf, Kurland, O Auld, and Paul, 1959).

In three dogs chlorpromazine ('largactil'), 2-5 mg./ kg., was injected intravenously. A previously effective dose of intravenous serotonin, 5-10 $\mu \mathrm{g} . / \mathrm{kg}$., was unable to raise the pulmonary artery pressure. yet hexadimethrine produced pulmonary hypertension.

The prolonged, delayed drop in systemic pressure, which we call the secondary or non-specific effect was abolished by antihistamine drugs; these had no effect on the primary (pulmonary hypertension) response.

COMPARISON WITH OTHER SUBSTANCES CAUSING PULMONARY HYPERTENSION AND RED CELL CLUMPING The injection of protamine, $5 \mathrm{mg}$. $/ \mathrm{kg}$., at the same rate as 
the standard hexadimethrine injection did not have a significant effect on pressures; but the intravenous injection of three times this dose caused a similar pattern of pressure changes.

The intravenous injection of hypertonic saline (20\%) caused a transient rise in pulmonary artery pressure with a fall in the systemic pressure. In contrast to the effect of hexadimethrine, in the lightly anaesthetized animal, this was accompanied by apnoea and bradycardia which could be modified by atropine. In contrast to Eliakim, Rosenberg, and Braun (1958), we found an acute drop in pulmonary vein pressure during this pulmonary artery hypertension caused by hypertonic saline.

BLOOD SAMPLES IN VIVO AND HISTOLOGICAL SAMPLES Arterial blood samples were collected during the control period, during the peak of pulmonary hypertension, and when pressures had returned to normal after the intravenous injection of hexadimethrine. The most striking feature was an acute drop in haematocrit during this pulmonary hypertension which returned to normal with the pressures. This drop was about $29 \%(12-47 \%)$ (Fig. 2). Similar though less marked changes were observed during the pulmonary hypertension caused by protamine and hypertonic saline. Control injections of normal saline of the same volume and speed of injection gave no measurable change in haematocrit. The left atrial haematocrit

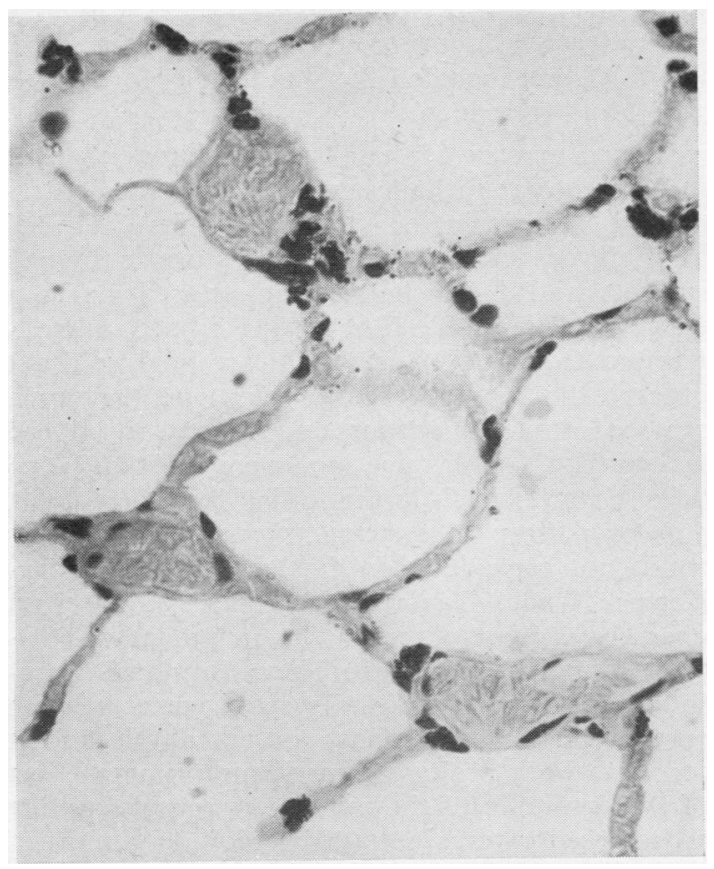

FIG. 5. Photomicrograph of segment of lung isolated at the time of pulmonary hypertension, showing capillaries stuffed with red cells.

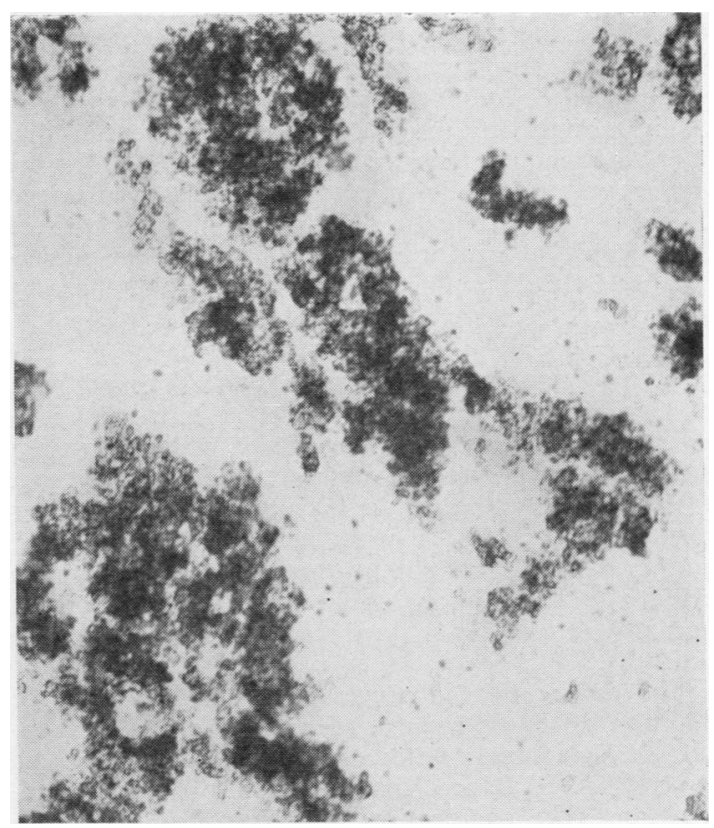

FIG. 6. Photomicrograph of red cells clumped in vitro by hexadimethrine bromide.

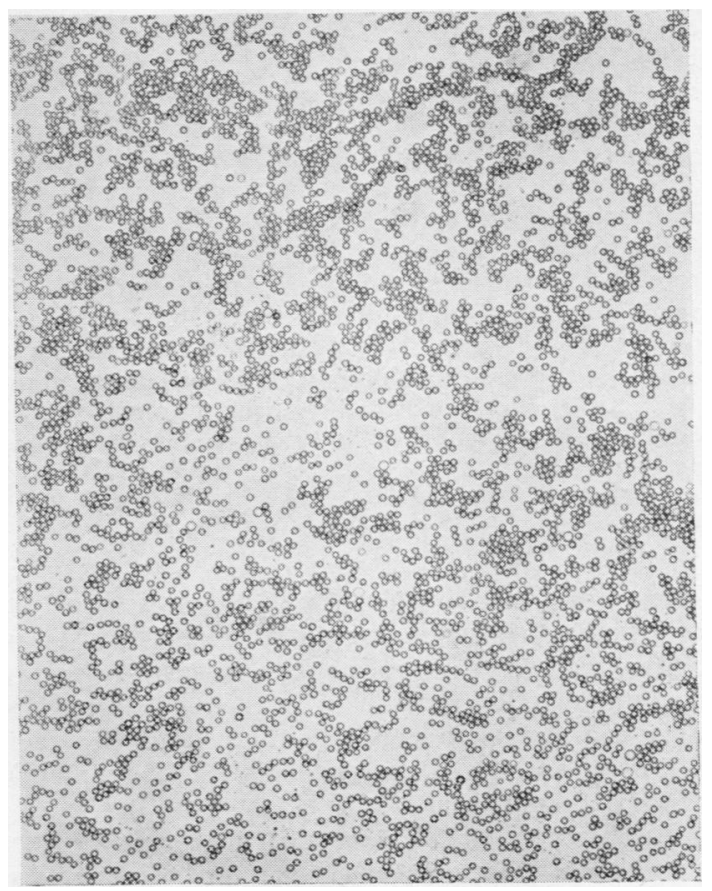

FIG. 7. Photomicrograph of red cells discrete again after the addition of heparin. 
was not changed during the pulmonary hypertension produced by the intravenous injection of serotonin.

Microscopic examination of sections of lung tissue taken during the peak of pulmonary hypertension due to hexadimethrine showed the vessels of all sizes stuffed with red cells in contrast to the appearance of the lung tissue before and after (Fig. 5). Direct microscopic observation of capillaries in the mesentery showed clumping after injections of hexadimethrine.

IN VITRO AGgREGATION OF RED CELlS The addition of hexadimethrine to blood in excess of a local concentration of $25 \mu \mathrm{g} . / \mathrm{ml}$. caused red cell aggregation into clumps that were clearly visible to the naked eye. Microscopically the red cells were heaped together in masses (Fig. 6). The white cells were not affected, and this is an excellent method of separating white cells. The aggregation occurs in citrated blood. It occurs with a saline or dextrose suspension of washed red cells.

The aggregation is prevented or reversed by the addition of excess heparin (Fig. 7). The further addition of hexadimethrine repeats the aggregation, which depends on the local concentration of free hexadimethrine. The aggregation is reflected by immediate sedimentation of the red cell clumps. This is restored to normal by an excess of heparin.

The addition of dextran to blood produced varying amounts of a finer textured aggregation. Low molecular weight dextran ('rheomacrodex') caused aggregation when large amounts were added to blood in excess of a proportion of three to one volumes.

Hypertonic saline, $20 \%$, and protamine in large amounts (which varied considerably with the batch) also caused aggregation, which on reversal was accompanied by haemolysis.

SPECIES DIFFERENCES Most species showed red cell aggregation with hexadimethrine. These included human blood and that of the $\operatorname{dog}$, cat, rat, and sheep. However, the blood of rabbits did not show this and injections of hexadimethrine into this species did not cause changes in the pulmonary artery pressure.

\section{DISCUSSION}

The main direct effect of the intravenous injection of hexadimethrine in the manner described is an acute rise in the pulmonary arterial pressure accompanied by a drop in pressure distal to the lung capillaries. In certain circumstances there is a second and more prolonged fall in the systemic arterial pressure.

Pulmonary hypertension occurs when the hexadimethrine has reached the lungs, and is due mainly to the temporary blockage, or stuffing, of a great number of blood vessels by aggregates of red cells formed by this substance. Support for this hypothesis comes from the following observations :

1. The time relation of the effect to the speed and distance of injection site from the lung.

2. It is always present in species that show red cell aggregation with hexadimethrine in vitro but not where this is absent.

3. It is not affected by atropine, vagotomy, antihistamines, and antagonists to the action on pulmonary circulation of 5-OH tryptamine.

4. The effect is abolished in vivo and in vitro by adequate amounts of heparin.

5. Pressure distal to the lung capillaries drops while the pulmonary arterial pressure is raised.

6. Histological sections of lung segments show the small vessels packed with red blood cells.

7. There is at the same time an acute drop in haematocrit in the left atrial blood corresponding with the pulmonary hypertension.

The prolonged delayed drop in systemic pressure without pulmonary hypertension is possibly due to a histamine reaction. It is seen typically only after first injections and in intact animals. It is subject to tachyphylaxis, as is common with histamine-releasing drugs (Macintosh and Paton, 1949), and is abolished or diminished by antihistamine drugs. It is probably responsible for the subjective symptoms described by Weiss et al. (1958). These included flushing, discomfort in the chest, and dyspnoea.

The occurrence of these two circulatory changes in different circumstances may explain the contradictory findings in the literature. Weiss described the delayed drop in systemic pressure in human subjects, and this is the reaction stressed by Egerton and Robinson (1961) using intact animals. Kimura et al. (1959), using intact animals, did not observe this reaction possibly because they used repeated small injections and thereby produced tachyphylaxis. They mention, in passing, that in two dogs, using a much larger initial dose, they got a prolonged drop in systemic pressure which they could not reproduce on further injection. MacKenzie, Wade, Davies, and Zellos (1961), with open-chest dogs, observed the pulmonary hypertension as the main effect. They also noted a profound and long fall in the systemic pressure with very large doses. We have observed this and it seems to be a prolongation of the primary effect of the damming of the pulmonary vessels causing a decreased cardiac output. In addition clumps of red cells can also be seen blocking the coronary arteries in this state.

Pulmonary hypertension with systemic hypotension were the primary reactions observed by 
Holemans and Adamis (1962) and by Rothnie and Kinmonth (1960).

There is considerable controversy as to the relative importance of mechanical blocking and vasoconstriction in pulmonary embolism (Aviado. 1962).

It has been suggested that the main circulatory effects in this condition are due to the release of 5-OH tryptamine (serotonin) (Comroe, Van Lingen, Stroud, and Roncoroni, 1953 ; Smith and Smith, 1955). We found that chlorpromazine, in doses large enuugh to abolish the circulatory effects of intravenous serotonin, had no effect on the pulmonary hypertension caused by hexadimethrine. It has also been suggested that serotonin produced red cell aggregation sufficient to cause pulmonary hypertension (Knisely, Wallace, and Addison, 1958), but Shepherd, Donald, Linder, and Swan (1959) showed that serotonin in dextrose without any red cells could produce pulmonary hypertension. Our observations did not suggest that serotonin produced pulmonary hypertension by red cell clumping.

As pointed out above, bilateral vagotomy and atropine did not modify the pulmonary hypertension caused by hexadimethrine.

We were interested in the mechanism of the production of pulmonary hypertension by red cell emboli, and in the possible bearing of this mechanism on clinical pulmonary embolism and hypertension, where the evidence suggests that both vasoconstriction and mechanical blocking play a part (Niden and Aviado, 1956) and that they potentiate each other. Thus vasoconstriction will cause smaller emboli to produce blockage. There is probably a complete range of varying degrees of constriction and mechanical blocking, from pure vasoconstriction to blocking by massive emboli, quite apart from the neuroreflexes affecting the heart.

Knisely, Wallace, Mahaley, and Satterwhite (1957) suggested that mechanical blocking rather than reflexes was often responsible for death in fatal pulmonary embolism. We found that red cell aggregation caused by hexadimethrine could produce so much blocking of the pulmonary vessels that the right ventricle was physically unable to overcome the resistance and the heart was forced to a standstill.

Increasing attention is being paid to the condition called obliterative pulmonary hypertension. In this the relatively capacious pulmonary vessels are gradually blocked by repeated small emboli until pulmonary hypertension occurs either at rest or with any increase in cardiac output. Patho- logical evidence shows that these showers of emboli may be clinically silent.

The demonstration that the aggregation of red cells in the veins can produce acute blocking of as capacious a circulatory field as the lungs emphasizes the possible importance of this factor in relation to such conditions as pulmonary hypertension, pulmonary embolism, and other disorders of the circulation associated with poor tissue perfusion and 'sludged' blood. Hexadimethrine can produce this aggregation, and the effects of this phenomenon on other organs are being studied. It is possibly not unrelated to the clinical phenomenon of 'sludging.'

The exact mechanism of red cell aggregation is not known. However, it seems that when it occurs naturally in vivo it is the result of an imbalance in the proteins of the plasma, due either to an initiation of the complex system of coagulation due to an upset of the dynamic equilibrium of the clotting-anticlotting factors and/or to the presence of abnormally large globulins. It is probably due to a change in the net surface charge of the red cells caused either by adsorption or chelation to a large suitably charged molecule. Washed red cells are, for instance, just as strongly aggregated by hexadimethrine.

The process can be prevented or reversed by the restoration of a normal balance in nett charge. Heparin restores the aggregation caused by hexadimethrine possibly by physical combination with the molecules. Low molecular dextran, which is used to prevent aggregation, probably acts by restoring the electrostatic status quo upset by the loss of albumin molecules and the consequent preponderance of larger molecules. This aspect is reported more fully in another paper. High concentrations of low molecular dextran actually cause aggregation (above $80 \%$ ). Low molecular dextran, $10-20 \mathrm{ml} . / \mathrm{kg}$., protected dogs from pulmonary hypertension due to the injection of hexadimethrine described above. The dose of the latter had to be increased threefold to get a standard response.

Other substances causing red cell aggregation have been studied and compared. These included dextran, large doses of protamine, and hypertonic solutions.

Our findings emphasize that red cell aggregation can be an important factor in impeding flow. This effect is increased by a low perfusion pressure, vasoconstriction or pre-existing increased resistance. It should be stressed that where these conditions exist, as in chronic pulmonary hypertension or after cardiopulmonary by-pass, hexadimethrine 
or other substances likely to produce red cell aggregation should be used with caution.

\section{SUMMARY}

Acute pulmonary hypertension can be caused by the rapid injection of hexadimethrine bromide ('polybrene'). The main circulatory effect is a rapid rise in the pulmonary artery pressure with a corresponding fall in the systemic pressure. Evidence is presented to show that this is mainly due to the blocking of the pulmonary vessels by red cell emboli caused by this substance. This red cell aggregation is shown in vitro and in vivo and is abolished by heparin.

A second type of non-specific circulatory effect consisting of a prolonged, delayed drop in systemic pressure is described.

The possible role of red cell aggregation in some forms of pulmonary embolism and hypertension is discussed, in the reference to the demonstration that red cell aggregation can produce a dramatic blockage of flow in as capacious a circulatory field as the lungs.

The dangers of injecting substances likely to cause red cell aggregation into the blood stream are emphasized.

We are grateful to Sir Russell Brock. Dr. Domingo Aviado, and Dr. Deuchar for their interest and help. and to Mr. P. Phelan and Miss Brown for technical assistance.

\section{REFERENCES}

Aviado, D. M. (1962). Some controversial cardiovascular reflexes. Circulat. Res., 10, 831 .
Comroe, J. H., Van Lingen, B., Stroud, R. C., and Roncoroni, A., (1953). Reflex and direct cardiopulmonary effects of 5-O.H.tryptamine (serotonin). Amer. J. Physiol., 173, 379.

Egerton, W. S., and Robinson, C. L. N. (1961). The anti-heparin., anticoagulant and hypotensive properties of hexadimethrine and protamine. Lancet, 2, 635 .

Eliakim, M., Rosenberg, S. Z., and Braun, K. (1958). Effect of hypertonic saline on the pulmonary and systemic pressures. Circulat. Res., 6, 357.

Gelin, L. E. (1956). Studies in anemia of injury. Acta chir. scand. Suppl. 210

Harris, P. (1957). Influence of acetylcholine on the pulmonary arterial pressure. Brit. Heart J., 19, 272.

Heimbecker, R. O and Bigelow, W. G. (1950). Intravascular agglutination of erythrocytes (sludged blood) and traumatic shock. Surgery, 28, 461.

Holemans, R., and Adamis, D. (1962). Hypotensive action of protamine and hexadimethrine. Lancet, 1, 434.

Kimura, E. T., Young, P. R., Stein, R. J., and Richards, R. K. (1959) Some pharmacologic characteristics of hexadimethrine brcmide (polybrene)-a new antiheparin agent. Toxicol.appl. Pharmacol. 1,185 .

Knisely, M. H. Eliot, T. S , and Bloch, E. H (1945). Sludged blood in traumatic shock. Arch. Surg., 51, 220.

Knisely, W. H., Wallace, J. M., and Addison, W. A. (1958). "Temporary" pulmonary embolization caused by intravenous injections of 5-hydroxytryptamine. Fed. Proc., 17, 88.

, - - Mahaley, M. S., and Satterwhite, W. M. (1957) Evidence, including in vivo observations, suggesting mechanical blockage rather than reflex vasospasm as the cause of death in pulmonary embolization. Amer. Heart J., 54, 483 .

Macintosh, F. C., and Paton, W. D. M. (1949). The liberation of histamine by certain organic bases. J. Physiol. (Lond.), 109, 190.

MacKenzie, G. J., Wade, J. D., Davies, S. H., and Zellos, S. (1961) The circulatory effects of hexadimethrine bromide (Polybrene) in dogs. Amer. Heart J., 62, 511.

Niden, A. H., and Aviado, D. M. (1956). Effects of pulmonary embolism on the pulmonary circulation with special reference to arteriovenous shunts in the lung. Circulat. Res. 4, 67

Preston, F. W. Hohf, R., and Trippel, O (1956). The neutralization of heparin with polybrene. Quart. Bull. Northw. Univ. med. Sch. 30, 138 .

Rothnie, N. J., and Kinmonth, J. B. (1960). The neutralization of heparin after perfusion. Brit.med. J., 2, 1194.

Rudolph, A. M., Kurland, M. D., Auld, P. A. M., and Paul, M. H. (1959). Effects of vasodilator drugs on normal and serotonin constricted pulmonary vessels of the dog. Amer. J. Physiol., 197, 617.

Shepherd, J. T . Donald D. E. Linder, E. and Swan, H. J. C. (1959). Effect of small doses of 5-hydroxytryptamine (serotonin) on pulmonary circulation in the closed-chest dog. Ibid., 197, 963 .

Smith, G., and Smith, A. N. (1955). The role of serotonin in experimental pulmonary embolism. Surg. Gynec. Obstet., 101, 691.

Weiss, W. A., Gilman, J. S., Catenacci, A., and Osterberg, A. E. (1958). Heparin neutralization with polybrene administered intravenously. J. Amer. med. Ass., 166, 603. 